\title{
EDITORIAL
}

\section{The new definition of pulmonary hypertension}

\author{
M.M. Hoeper
}

D espite the progress that has been made in the field of pulmonary hypertension $(\mathrm{PH})$ [1-3], there is no unifying and globally accepted definition of the condition. The first official haemodynamic definition of $\mathrm{PH}$ was proposed at the First World Symposium on Pulmonary Hypertension which took place 1973 in Geneva, Switzerland as a World Health Organization (WHO)-sponsored meeting [4]. This conference was triggered by the previous epidemic of $\mathrm{PH}$ associated with the appetite suppressant aminorex [5]. As such, the focus of that meeting was primary pulmonary hypertension (PPH), as compared to the other forms of $\mathrm{PH}$. After a long and sometimes heated debate the consensus was to define PPH by a mean pulmonary artery pressure $\left(\bar{P}_{\mathrm{pa}}\right)$ $>25 \mathrm{mmHg}$ at rest or $>30 \mathrm{mmHg}$ during exercise in the presence of a pulmonary capillary wedge pressure $(\mathrm{Ppcw})$ $\leqslant 15 \mathrm{mmHg}$.

This definition was later extended to other forms of pulmonary arterial hypertension (PAH) [6]. It stood the test of time for $>30$ yrs, but was challenged during the Fourth World Symposium on Pulmonary Hypertension, which took place 2008 in Dana Point, CA, USA. There were several reasons for this: 1) the old definition did not take into account other forms of PH; 2) the threshold of $\bar{P}_{\mathrm{pa}}>25 \mathrm{mmHg}$ at rest does not reflect the upper limit of normal; 3) clinically relevant $\mathrm{PH}$ can be present, despite the $\bar{P}_{\text {pa being }}<25 \mathrm{mmHg}$ at rest; 4 ) the cutoff value of $30 \mathrm{mmHg}$ during exercise was arbitrarily chosen and not supported by published data; and 5) $\mathrm{PH}$ is often present in conjunction with elevated $P$ pcw levels.

Some of these points are addressed in a paper by Kovacs et al. [7] published in the present issue of the European Respiratory Journal. In preparation for the Dana Point meeting, they performed a comprehensive review of the literature published since 1947 in English, German or French language searching for right heart catheterisations performed in healthy individuals. Altogether, they were able to identify data obtained from 1,187 individuals in 47 studies. A meta-analysis of these data showed that the normal $\bar{P}_{\mathrm{pa}}$ at rest is $14.3 \pm 3.3 \mathrm{mmHg}$. These values are virtually age-independent. Following the customary approach to define an upper level of normal as the mean plus two standard deviations, the upper level of normal for the $\bar{P}$ pa at rest would be $20 \mathrm{mmHg}$. However, provided that the $P$ pa is normally distributed, one in 40 healthy people will be above this threshold, i.e. 25,000 per million population. Even if the threshold is increased to $25 \mathrm{mmHg}$, the theoretical prevalence of individuals above this level would still be far

CORRESPONDENCE: M.M. Hoeper, Dept of Respiratory Medicine, Hannover Medical School, CarlNeuberg-Str. 1, 30625 Hanover, Germany. E-mail: hoeper.marius@mh-hannover.de beyond the known prevalence of PAH. Conversely, some studies indicate that even $\bar{P}$ pa $>17-20 \mathrm{mmHg}$ may be associated with a poor prognosis, especially in patients with chronic lung diseases [8-11]. As is often the case in medicine, there exists a grey zone where a given value can be considered high, normal or already pathological, depending on the clinical context.

Of equal importance, the findings by Kovacs et al. [7] challenge the exercise component of the old $\mathrm{PH}$ definition. The problem with the 1973 WHO consensus was that the cut-off level of $30 \mathrm{mmHg}$ during exercise was not supported by evidence. Kovacs et al. [7] show that, in younger persons aged $<50$ yrs, $\bar{P}_{\mathrm{pa}}$ of $35 \mathrm{mmHg}$ can be considered normal during sub-maximal or maximal exercise. More importantly, in contrast to the $P$ pa at rest, the $P$ pa during exercise is largely age-dependent, presumably as a result of increasing stiffness of the left ventricle and the pulmonary vessels. $\bar{P}$ pa $>30 \mathrm{mmHg}$ during mild exercise is seen in $\sim 50 \%$ of apparently healthy subjects aged $>50$ yrs, and $\bar{P}_{\text {pa }}$ up to $45 \mathrm{mmHg}$ during exercise appear to be normal in this population. Thus, with the previous definition many individuals were incorrectly labelled as pulmonary hypertensive that in fact had simply a physiological exercise response. Taking into account all these variables, it seems impossible to come up with a solid definition of $\mathrm{PH}$ during exercise. Further research is ongoing in this field to generate the data that are needed to move forward in this important area of pulmonary vascular disease $[12,13]$.

The consequences of the findings by Kovacs et al. [7] were intensively discussed at the Fourth World Symposium on Pulmonary Hypertension in Dana Point and it was decided to abandon the exercise criterion. With regard to the definition of $\mathrm{PH}$ at rest, it was proposed to introduce the term "borderline $\mathrm{PH}^{\prime \prime}$ for patients with $\bar{P}_{\mathrm{pa}} 20-25 \mathrm{mmHg}$, but this term was eventually rejected, as it was felt that patients presenting with $P_{\mathrm{pa}}$ in this range should be further studied before being labelled with a diagnosis of $\mathrm{PH}$. Thus, in the proceedings of the Dana Point meeting, the new haemodynamic definition of $\mathrm{PH}$ will be a $\bar{P}_{\text {pa }}$ at rest $\geqslant 25 \mathrm{mmHg}$ [14]. This definition, which covers all forms of $\mathrm{PH}$, will be adopted by the revised joint $\mathrm{PH}$ guidelines of the European Society of Cardiology and the European Respiratory Society, in which PH will be divided into pre-capillary and post-capillary forms, based on whether mean $P$ pcw is $\leqslant 15$ or $>15 \mathrm{mmHg}$, respectively $[15,16]$.

The revised haemodynamic definition of $\mathrm{PH}$ constitutes an improvement over the old definition, since it takes into account recent data and has broader applicability. Abandoning the exercise criterion is justified by the findings of Kovacs et al. [7] and it will prevent many false diagnoses of $\mathrm{PH}$, as well as unjustified therapies. Limiting the current $\mathrm{PH}$ definition to a 
$\bar{P}_{\text {pa }}$ at rest $\geqslant 25 \mathrm{mmHg}$ is also comprehensible for the time being. All treatment studies performed so far in the field of $\mathrm{PH}$ have included only patients fulfilling this criterion. Milder forms of $\mathrm{PH}$, i.e. resting $\mathrm{P}$ pa $20-25 \mathrm{mmHg}$, are usually found among patients with underlying lung or heart disease, and medical therapies for these forms of $\mathrm{PH}$ have not been sufficiently studied. Eventually, with the broadening of our knowledge, the PH definition may have to be revised again.

KovAcs et al. [7] are to be commended for their invaluable contribution and it is likely that their manuscript will serve as a reference paper for a very long time.

\section{STATEMENT OF INTEREST}

A statement of interest for M.M. Hoeper can be found at www.erj. ersjournals.com/misc/statements.dtl

\section{REFERENCES}

1 Dupuis J, Hoeper MM. Endothelin receptor antagonists in pulmonary arterial hypertension. Eur Respir J 2008; 31: 407-414.

2 Wilkins MR, Wharton J, Grimminger F, et al. Phosphodiesterase inhibitors for the treatment of pulmonary hypertension. Eur Respir J 2008; 32: 198-209.

3 Olschewski H, Gomberg-Maitland M. Prostacyclin therapies for the treatment of pulmonary arterial hypertension. Eur Respir J 2008; 31: 801-901.

4 Hatano S, Strasser T. Primary Pulmonary Hypertension: Report on a WHO Meeting, Geneva 15-17 October 1973. Geneva, World Health Organization, 1975.

5 Bass O, Gurtner HP. [Evolution of primary vascular pulmonary hypertension following ingestion of aminorex fumarate (Menocil).
Preliminary communication]. Schweiz Med Wochenschr 1973; 103: 1794

6 Galie N, Torbicki A, Barst R, et al. Guidelines on diagnosis and treatment of pulmonary arterial hypertension. The Task Force on Diagnosis and Treatment of Pulmonary Arterial Hypertension of the European Society of Cardiology. Eur Heart J 2004; 25: 2243-2278.

7 Kovacs G, Berghold A, Scheidl S, et al. Pulmonary arterial pressure during rest and exercise in healthy subjects: a systematic review. Eur Respir J 2009; 34: 888-894.

8 Behr J, Ryu JH. Pulmonary hypertension in interstitial lung disease. Eur Respir J 2008; 31: 1357-1367.

9 Chaouat A, Naeije R, Weitzenblum E. Pulmonary hypertension in COPD. Eur Respir J 2008; 32: 1371-1385.

10 Oswald-Mammosser M, Weitzenblum E, Quoix E, et al. Prognostic factors in COPD patients receiving long-term oxygen therapy. Importance of pulmonary artery pressure. Chest 1995; 107: 1193-1198

11 Hamada K, Nagai S, Tanaka S, et al. Significance of pulmonary arterial pressure and diffusion capacity of the lung as prognosticator in patients with idiopathic pulmonary fibrosis. Chest 2007; 131: 650-656.

12 Oudiz RJ, Rubin LJ. Exercise-induced pulmonary arterial hypertension: a new addition to the spectrum of pulmonary vascular diseases. Circulation 2008; 118: 2120-2121.

13 Tolle JJ, Waxman $\mathrm{AB}$, Van Horn $\mathrm{TL}$, et al. Exercise-induced pulmonary arterial hypertension. Circulation 2008; 118: 2183-2189.

14 Badesch DB, Champion HC, Gomez-Sanchez MA, et al. Diagnosis and assessment of pulmonary arterial hypertension. J Am Coll Cardiol 2009; 54: Suppl., S55-S66.

15 Galie N, Hoeper MM, Humbert M, et al. Guidelines on the diagnosis and treatment of pulmonary hypertension. Eur Respir J 2009; In press.

16 Galie N, Hoeper MM, Humbert M, et al. Guidelines on the diagnosis and treatment of pulmonary hypertension. Eur Heart $J$ 2009; In press. 